Article

\title{
The Impact of Node Location Imperfections on the Reliability of Single-Layer Steel Domes
}

\author{
Paweł Zabojszcza *(i) and Urszula Radoń \\ Faculty of Civil Engineering and Architecture, Kielce University of Technology, al. Tysiąclecia Państwa \\ Polskiego 7, 25-314 Kielce, Poland \\ * Correspondence: zabojszcza.pawel@gmail.com
}

Received: 4 June 2019; Accepted: 3 July 2019; Published: 6 July 2019

Featured Application: The effect of imperfections of node locations on the reliability of single-layer steel domes is a very important issue in the design of steel structures. This paper shows that, with reliability analysis methods, it is possible to analyze the failure probability level while moving along the load displacement path towards the limit point. In this paper, the impact of changes in the standard deviation of random variables describing coordinates of nodes on the reliability index $\beta$ of the single-layer steel dome was analyzed. The changes in the standard deviation of variables describe imperfections of node locations. Reliability analysis is also employed to find sensitivity of the reliability index to mean values or standard deviation of random variables by calculating the elasticity index. This method can be used to design single-layer steel domes.

\begin{abstract}
This study is an attempt to assess the effect of node location imperfections on the reliability dome. The analysis concerns a single-layer steel lattice dome that is very sensitive to node snap-through. The load-displacement path of the structure was determined using the program, Finite Element Method-Krata. To determine the failure probability, reliability index, and elasticity index, the first-order reliability method approximation method was employed. The reliability analysis was conducted with Numpress Explore software, developed at the Institute of Fundamental Technological Research of the Polish Academy of Sciences, Warsaw. In this paper, it is shown how large differences in the assessment of the safety of a structure can appear when we incorrectly estimate the standard deviation of the random variable responsible for the imperfections of node locations.
\end{abstract}

Keywords: single-layer lattice domes; reliability index; elasticity index; first-order reliability method

\section{Introduction}

The reliability theory is a well-established research area. The most well-known textbooks and monographs are: Madsen, Krenk, and Lind [1], Melchers [2], Ditlevsen and Madsen [3], Thoft-Christensen and Baker [4], and Augusti, Baratta, and Casciati [5]. Special attention should be paid to publications by Harr [6] and Nowak and Collins [7]. These publications present the basic concepts of reliability theory with a particular reference to their uses in civil engineering. The work of Hasofer and Lind [8], published in 1974, is recognized as the first important step towards the contemporary methods that make it possible to effectively and accurately estimate structural safety. Hasofer and Lind developed the concept of localization of the so-called 'design point', i.e., such realization of random variables from the failure surface, which corresponds to the greatest value of the probability density function. With the linearization of the limit state function at the design point, it is possible to obtain a measure of reliability that is invariant, due to the equivalent formulations of the boundary condition, i.e., the so-called Hasofer-Lind reliability index. The lack of invariance was the 
basic shortcoming of the previously applied Cornell index [9]. It was difficult to use this measure of reliability for comparison of the degrees of safety of different structures.

The concept of the Hasofer-Lind index was used in 1978 by Rackwitz and Fiessler in [10]. Additionally, they applied transformations of independent random variables with arbitrary probability distributions to standard normal variables and they proposed an algorithm of the approximation of the design point. In [11], Hohenbichler and Rackwitz proposed the utilization of Rosenblatt's transformation [12] to the transformation of dependent random variables to standard space. Rosenblatt and Nataf's transformations, applied for the first time by Der Kiureghian and Liu in [13], are most frequently used at present. They make it possible to analyze reliability problems, both when the joint probability density function of random variables, as well as the marginal probability density function of variables, and correlation matrix are known. The approximation of the limit state function at the design point by the function of the first or second degree leads to the first-order reliability method (FORM) or the second-order reliability method (SORM).

In the early applications of the FORM and SORM methods, it was most often assumed that the limit state function was an explicit function of random variables. Unfortunately, with the exception of a few simple examples, such functional dependency cannot be specified, and in most cases it is given through a definite numerical procedure, e.g., the finite element method [14-16]. However, with the first studies of Der Kiureghian and collaborators, the problems of the utilization of the finite element method in reliability analysis began to be very intensely developed. An overview and test of different discretization methods can be found in the works of Li and Der Kiureghian [17] and Matthies [18]. Popular reliability analysis codes, such as ANSYS PDS, DesignXplorer, CalREL/FERUM/OpenSees, COSSAN, NESSUS, PERMAS-RA/STRUREL, PHIMECA-SOFT, PROBAN, PROFES, and UNIPASS, are reviewed in [19-28].

The separate group of reliability analysis methods are simulation methods. The classical Monte Carlo method is best known. In the Monte Carlo simulation method, the estimation of failure probability consists in the $\mathrm{n}$-th generation of basic random variables, in conformity with their joint probability density function and determination of the number of hits in the failure area. The lower the probability of failures that we want to estimate, the more simulations ought to be carried out, so that the error of this estimation could be situated in a fairly small trust range with a sufficiently high probability. With a predicted failure, with the probability of building structures of the range from $10^{-4}$ to $10^{-7}$, the number of necessary simulations is estimated to be from $10^{6}$ to $10^{9}$, which is a huge task even for modern computers, and is hardly feasible in acceptable time. The computational outlay disqualifies, in the opinion of the author, the usefulness of the classical Monte Carlo method for the analysis of practical problems of the reliability of building structures. The 1980s marked the development of the so-called importance sampling method. Through a proper selection of probability density function, according to which random variables are generated, one can significantly decrease the sampling area and the number of simulations. Articles by Schuëller and Stix [29], Hohenbichler and Rackwitz [30], and Dolinski [31] stand out in works devoted to this method. Another variety of simulation methods is the directional sampling method. It is best applicable for the analysis of problems in which the limit area has a shape close to a hypersphere. An overview of various simulation methods can be found in the works of Rubinstein [32] and Melchers [2]. In the present paper, simulation methods are not used. The basic research tool is one of the approximation methods-FORM.

The purpose of this article is an estimation of the influence of node location imperfections on the reliability of single-layer steel domes. They are subjected to big displacement gradients and are susceptible to stability loss from the condition of node snapping. When designing such structures, it is also possible to buckle individual bars locally. However, this is not a form of loss of stability that determines the load-bearing capacity of the structure. These truss structures are extremely sensitive, even to the slight changing of node locations [33-35]. Therefore, the imperfection description is very important for the correct design of such structures. In the analysis by means of the finite element method we used a space truss element, which is a simple two-node element with three degrees of 
freedom in each node. The shape functions of the displacement field are linear. The displacement field of an element contains three translational components: $\mathrm{u}$ and $\mathrm{v}$ and $\mathrm{w}$. The strain tensor is reduced to one non-zero component of Green's strain tensor $\varepsilon_{11}$, which characterizes the elongation of the bar. Other components of the strain tensor are equal to 0 . The stress tensor is represented by the component $\sigma_{11}$ of Pioli-Kirchhoff's second stress tensor. The stress-strain relationship is linear. In the paper, nonlinear geometrical relations are defined in the Lagrangian description. The stability analysis of structures by means of the finite element method involves the solution of large systems of nonlinear equations. The load-displacement history of a structure presents a curve in a $(\mathrm{N}+1)$ dimensional space, called the equilibrium path. In this paper, the constant arc length method (Riks [36,37]) is used for the determination of the equilibrium path. The problem of elastic stability is intimately connected with singularities that occur along the path. These singular points are referred to as critical points. The classification of critical points includes limit points and bifurcation points that are connected with the physical concepts of snapping and buckling, respectively [38-41].

Let us now ask a question: What is the advantage of the inclusion of reliability analysis methods to the analysis of stability? Using methods of reliability analysis, we can determine the level of failure probability when we approach the critical point. This is a quantitative assessment. Reliability analysis is also employed to find the sensitivity of the reliability index to mean values or standard deviation of random variables by calculating the elasticity index. This paper shows large differences in the assessment of how the safety of a structure can appear when we incorrectly estimate the standard deviation of the random variable responsible for the imperfections of node locations. The reliability analysis is conducted with Numpress Explore software, developed at the Institute of Fundamental Technological Research of the Polish Academy of Sciences, Warsaw [42-45].

The calculations are carried out in two steps. The first (deterministic) step, is directed towards finding the coordinates of the limit point on the equilibrium path, using the program Finite Element Method-Krata. These coordinates are necessary to determine the parameters of the limit function in the reliability analysis. The second step includes the connection of Numpress Explore with Krata. This analysis allows us to estimate the reliability index, elasticity index, and probability of failure.

\section{Reliability and Elasticity Indexes}

To conduct the reliability analysis is to find out how the structure state is affected by the random character of structure-describing parameters $X_{1}, X_{2}, \ldots, X_{n}$. The parameters can include material constants, loads, and geometric ratios.

Those parameters can be grouped into the column vector (the random vector) $X=\left\{X_{1}, X_{2}, \ldots\right.$, $\left.X_{n}\right\}$, where: $X_{1}, X_{2}, \ldots, X_{n}$ are successive single-dimensional random variables (the basic random variables). In this defined $\mathrm{n}$-dimensional real space $R^{\mathrm{n}}$, the random vector takes on an indefinite number of single sets of values of individual basic random variables that are equal to: $x_{1}, x_{2}, \ldots$, $x_{n}$, respectively. A single set, $x=\left\{x_{1}, x_{2}, \ldots, x_{n}\right\}$, is called the realization of the random vector $X$. The realization $x$ of the vector $\boldsymbol{X}$ belongs to Euclidean space. The assessment of the structure state is possible, due to the failure criterion imposed by the designer (random limit function $g(X)$ ). It is usually a stress or displacement criterion. The values of the limit function divide the space as follows:

$$
\begin{gathered}
g(\mathbf{x}) \leq 0-\text { failure area } \Omega_{\mathrm{f}} \\
g(\mathbf{x})>0-\text { safe area } \Omega_{\mathrm{S}} \\
g(\mathbf{x})=0-\text { limit area }
\end{gathered}
$$

Using the definition of boundary conditions, failure probability is the probability of a random event specified by the failure area:

$$
P_{\mathrm{f}}=P(g(\mathbf{x}) \leq 0)
$$


Alternatively, failure probability can be expressed by an integral:

$$
P_{\mathrm{f}}=\int \Omega \mathrm{f} f(\mathbf{x}) \mathrm{dx}
$$

where $f(\mathbf{x})=f\left(\mathbf{x}_{1}, \mathbf{x}_{2}, \ldots, \mathbf{x}_{\mathrm{n}}\right)$ denotes the joint probability density function of random parameters.

The reliability of the structure is the probability of the occurrence of the realizations of basic variables $X$ in the area, which ensures safe performance of the structure.

The nature of the concept above is illustrated in Figure 1. In the two-dimensional space of random variables, $X=\left\{X_{1}, X_{2}\right\}$, the sets and contours of the joint probability density function $f_{X}\left(x_{1}, x_{2}\right)$ were marked.

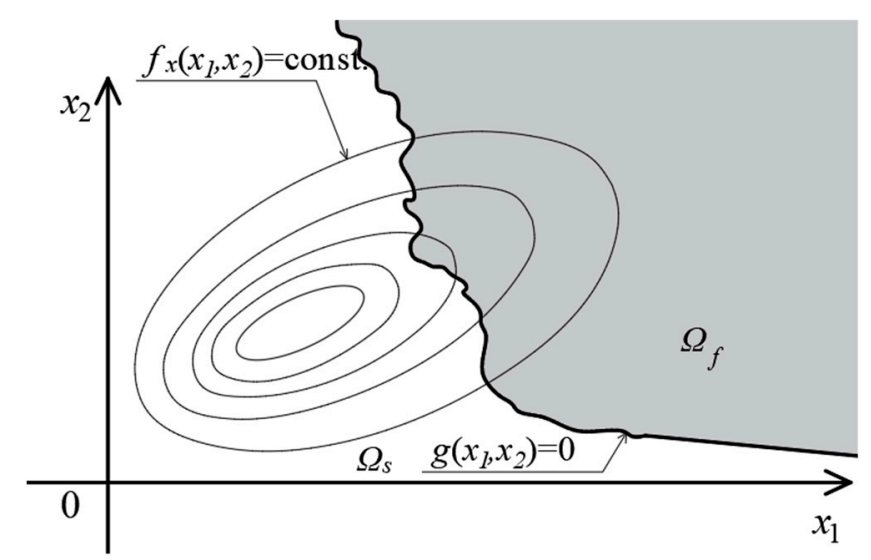

Figure 1. Limit area $g(\mathbf{x})=0$, safe area $\Omega_{\mathrm{S}}$ and failure area $\Omega_{\mathrm{f}}$ in the space of random variables $X$.

The values of failure probability of a building are equal from $1 \cdot 0 \cdot 10^{-7}$ to $6.9 \cdot 10^{-4}$ [46]. Relying on such values could be problematic. Consequently, a reliability measure (the reliability index $\beta=$ $\left.-\Phi^{-1}\left(P_{\mathrm{f}}\right)\right)$ was introduced, where $\Phi^{-1}$ is the inverse function of the standard normal distribution function. From the technical standpoint, the most relevant problem concerns the means of the integral value determination. A large number of variables and the implicit form of the function $g(\mathbf{X})$ make it impossible to numerically integrate the expression. The reliability analysis of real structures was conducted using the approximation and simulation methods. In this group of methods, a key factor was the time of computations. Roughly speaking, it was the time necessary to obtain a single value of the function $g(\mathbf{x})$ (corresponding to realization $\mathbf{x}$ ) multiplied by the number of realizations required to estimate $P_{\mathrm{f}}$. The values of the function $g(\mathbf{x})$ were computed using Krata.

In this study, the FORM was employed to determine the reliability index. The FORM is one of the most effective tools for calculating approximate reliability measures. In general, when the vector of basic variables $X$ is not a Gaussian, random variables are transformed to the standard Gaussian space $\mathbf{Z}$.

The probability of failure, defined in space $X$, must be equal to the probability defined in space $Z$.

$$
P_{\mathrm{f}}=\int_{\Omega \mathrm{f}} f_{x}(\mathbf{x}) \mathrm{d} \mathbf{x}=\int_{\Delta_{\mathrm{f}}} \prod_{\mathrm{i}=1}^{\mathrm{n}} \varphi\left(\mathrm{z}_{\mathrm{i}}\right) \mathrm{d} \mathrm{z}_{1} \mathrm{~d} \mathrm{z}_{2} \ldots \mathrm{d} \mathrm{z}_{\mathrm{n}}
$$

We can write the transformation of regions as:

$$
\begin{aligned}
& \Omega_{\mathrm{f}}=\{\mathbf{x}: g(\mathbf{x}) \leq 0\} \rightarrow \Delta_{\mathrm{f}}=\{\mathbf{z}: \mathrm{G}(\mathbf{z}) \leq 0\} \\
& \Omega_{\mathrm{s}}=\{\mathbf{x}: g(\mathbf{x})>0\} \rightarrow \Delta_{\mathrm{s}}=\{\mathbf{z}: \mathrm{G}(\mathbf{z})>0\}
\end{aligned}
$$

The limit state function is transformed in this way:

$$
g(\mathbf{x})=0 \rightarrow g\left[T^{-1}(\mathbf{z})\right]=\mathrm{G}(\mathbf{z})=0
$$


The reliability analysis problem was formulated using the limit function $G(\mathbf{Z})$. The transformation of the basic random variables to the standard Gaussian space must ensure that the reliability problem is formulated in an equivalent way. In the FORM, after random variables had been transformed to the standard space $\mathbf{Z}$, the limit surface $G(\mathbf{z})=0$ was approximated with a hyperplane that was tangent to the surface at the design point (Figure 2). The hyperplane is described by this equation:

$$
1(\mathbf{Z})=-\alpha^{\mathrm{T}} \cdot \mathbf{Z}+\beta
$$

where $\alpha=-\left.\frac{\nabla G(\mathbf{z})}{\|\nabla G(\mathbf{z})\|}\right|_{\mathbf{z}=\mathbf{z}^{*}}$ and $\beta=\operatorname{sign}[1(0)] \delta^{*}$ is the Hasofer-Lind reliability index, related to $\delta^{*}$, i.e., the hyperplane distance $1(z)=0$ from the origin of the coordinate system and $\alpha$-unit vector, the direction of which is opposite to the $G(\mathbf{z})$ function gradient at the design point.

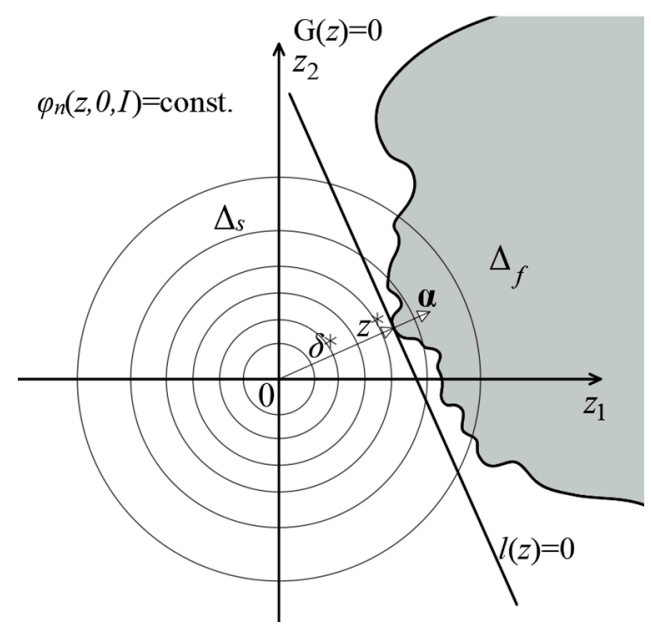

Figure 2. The approximation of the first order of the probability value.

Thus, the FORM changed the problem of failure probability integration into an issue that concerned finding the design point, the calculations for which could be performed using an optimization algorithm with inequality limitations $[47,48]$. An advantage offered by the FORM is the possibility of determining sensitivity to the change of parameters without making additional calculations. The fact that sensitivity of the reliability index is known becomes of key importance for reliable optimization, forecasting trends in the optimization process, and for initial considerations when the stochastic model is developed. If the sensitivity of the reliability index to random variable $X_{i}$ is low compared to other variables, it is possible to acknowledge that the effect of this variable on the failure probability value is small. Consequently, in subsequent computations it can be treated as a deterministic variable. For the sake of interpretation and comparison, a normalized sensitivity measure, namely the elasticity index $\mathrm{E}_{\beta}\left(\mathrm{p}_{\mathrm{i}}\right)$, was introduced.

The elasticity index $E_{\beta}\left(p_{i}\right)$ can be defined as the percentage change in the reliability index $\beta$ (Figure 3]. This article assumes that the $p_{i}$ parameter changes by $1 \%$. We can determine this value depending on our needs. 


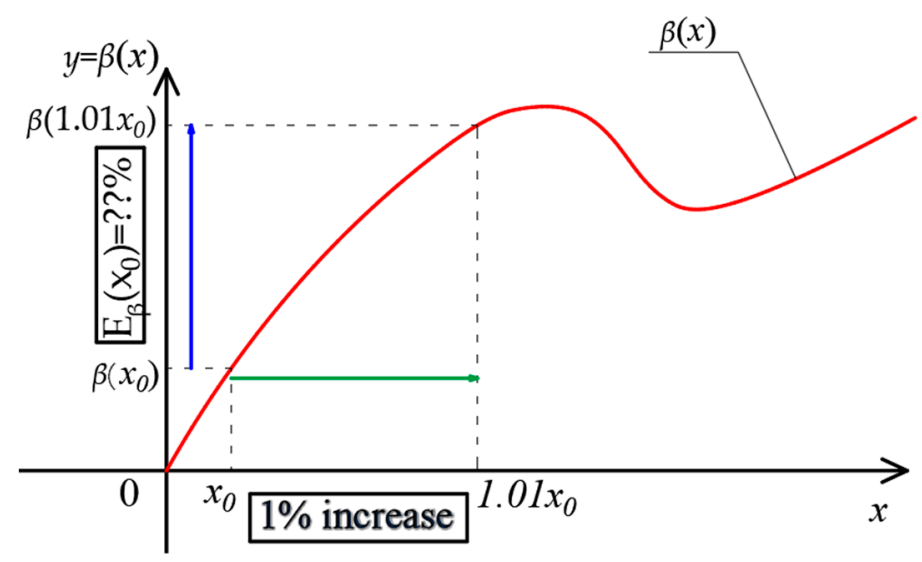

Figure 3. Illustration of the elasticity of the function $\beta(\mathrm{x})$ of one variable $\mathrm{x}$.

The indicator $\mathrm{E}_{\beta}\left(\mathrm{p}_{\mathrm{i}}\right)$ allowed us to describe the sensitivity of the reliability index to changes in all random parameters $p_{i}[49]$. It can be written as follows:

$$
\mathrm{E}_{\beta}\left(\mathrm{p}_{\mathrm{i}}\right)=\frac{\partial \beta}{\partial \mathrm{p}_{\mathrm{i}}} \frac{\mathrm{p}_{\mathrm{i}}}{\beta}
$$

For examples:

with standard deviation:

$$
\mathrm{E}_{\beta}\left(\sigma_{i}\right)=\frac{\partial \beta}{\partial \sigma_{i}} \frac{\sigma_{i}}{\beta}
$$

or with mean value:

$$
\mathrm{E}_{\beta}(\overline{\mathrm{Xi}})=\frac{\partial \beta}{\partial \overline{\mathrm{X}_{\mathrm{i}}}} \frac{\overline{\mathrm{Xi}}}{\beta}
$$

In a stochastic model, the variable $p_{i}$ can determine a standard deviation $\sigma_{\mathbf{i}}$ or a mean value $\overline{X_{i}}$. In this article, both variables are used.

\section{Numerical Results and Discussion}

A mesh of the lattice dome, consisting of 25 nodes and 56 elements, is illustrated in Figure 4 . The dome geometry is shown in Table 1 . The elements of the structure were assumed to be made of steel tubes RO $101.6 \times 6$ with yield point $f_{\mathrm{y}}=235 \mathrm{MPa}$ and Young's modulus $E=210 \mathrm{GPa}$. The load of the $\mu \cdot P$ value was applied to the keystone $(P=1 \mathrm{kN})$. 
Table 1. Geometry of the lattice dome.

\begin{tabular}{cccccccc}
\hline $\begin{array}{c}\text { No. of } \\
\text { Node }\end{array}$ & $x[\mathrm{~m}]$ & $\boldsymbol{y}[\mathrm{m}]$ & $z[\mathrm{~m}]$ & $\begin{array}{c}\text { No. of } \\
\text { Node }\end{array}$ & $\boldsymbol{x}[\mathrm{m}]$ & $\boldsymbol{y}[\mathrm{m}]$ & $z[\mathrm{~m}]$ \\
\hline 1 & 15.000 & 15.000 & 1.6465 & 14 & 5.761 & 11.173 & 1.14 \\
2 & 20.000 & 15.000 & 1.432 & 15 & 5.761 & 18.827 & 1.14 \\
3 & 18.536 & 11.464 & 1.432 & 16 & 11.173 & 24.239 & 1.14 \\
4 & 15.000 & 10.000 & 1.432 & 17 & 18.827 & 24.239 & 1.14 \\
5 & 11.464 & 11.464 & 1.432 & 18 & 30.000 & 15.000 & 0 \\
6 & 10.000 & 15.000 & 1.432 & 19 & 25.607 & 4.393 & 0 \\
7 & 11.464 & 18.536 & 1.432 & 20 & 15.000 & 0.000 & 0 \\
8 & 15.000 & 20.000 & 1.432 & 21 & 4.393 & 4.393 & 0 \\
9 & 18.536 & 18.536 & 1.432 & 22 & 0.000 & 15.000 & 0 \\
10 & 24.239 & 18.827 & 1.14 & 23 & 4.393 & 25.607 & 0 \\
11 & 24.239 & 11.173 & 1.14 & 24 & 15.000 & 30.000 & 0 \\
12 & 18.827 & 5.761 & 1.14 & 25 & 25.607 & 25.607 & 0 \\
13 & 11.173 & 5.761 & 1.14 & & & & \\
\hline
\end{tabular}

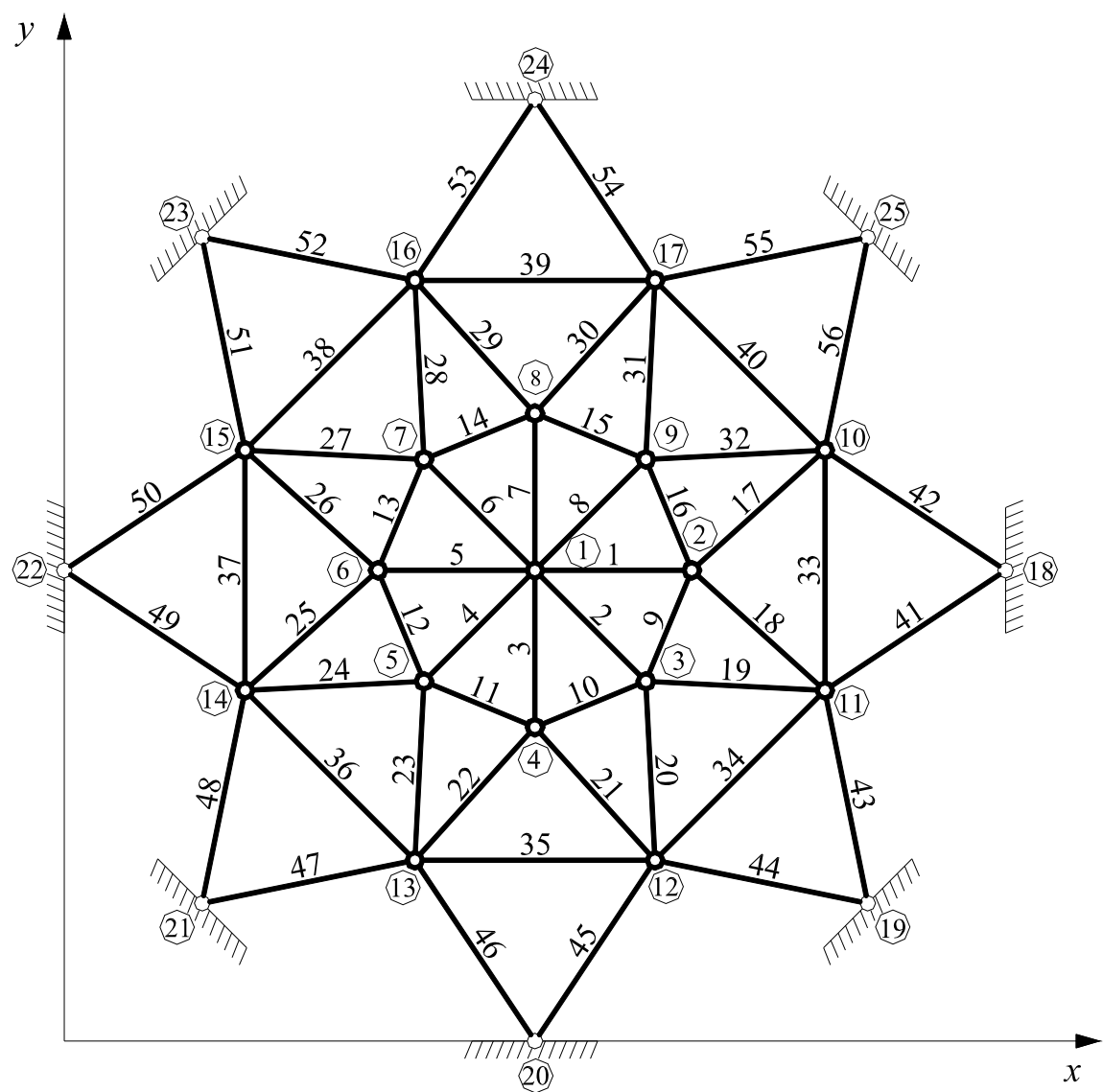

Figure 4. Mesh of the lattice dome elements.

In the first deterministic step, the Krata software [50-52] was used to determine the load-displacement path and the value of the limit load multiplier $\mu_{\mathrm{cr}}=26.15 \mathrm{kN}$. Figure 5 shows the dependence between the value of the load multiplier $\mu$ and the vertical displacement of node No. 1- $q_{1}$. In this paper, the constant arc length method is used for determination of the equilibrium path. 


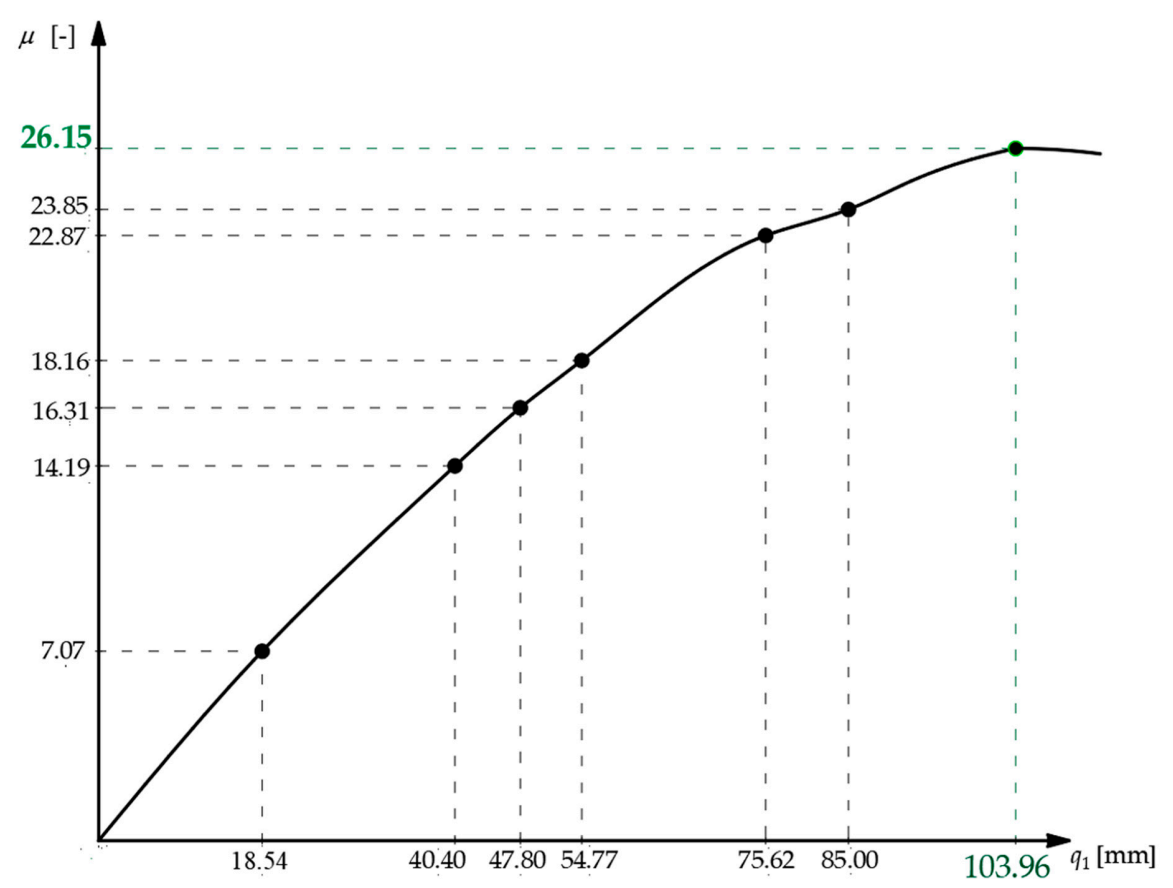

Figure 5. The dependence between the value of the load multiplier $\mu$ and the vertical displacement $q_{1}$.

The second step started with the creation of a stochastic model in the Numpress Explore program [53]. Based on the coordinates of the limit point, the form of the limit function was formulated as a condition of non-exceedance of the admissible multiplier of the vertical load on node No. 1:

$$
g_{\mu}(\mathbf{x})=1-\mu(\mathbf{x}) / 26.15
$$

The alternative version of the limit state function could be the condition of non-exceedance of the vertical displacement $q_{1}$ on node No.1:

$$
g_{q 1}(\mathbf{x})=1-q_{1}(\mathbf{x}) / 103.96
$$

The software allowed us to define two types of random variables, namely, basic and external. When the reliability analysis was conducted, the following basic random variables were taken into account: load $P$, coordinates $Z_{i}$ of nodes $i=1, \ldots, 17$. Basic random variables were not correlated. Their description is shown in Table 2 . The external variables were implicit functions of basic random variables, the values of which were obtained with the Krata software. In this paper, the external variable is the load multiplier $\mu$. Figure 6 shows the procedure of the analysis. The values of external variables were read from the text sets that contained the results of computations with the Krata software. The next step involved the introduction of the limit function formula, using the standard mathematical notation as a dependence on basic and external random variables. In the study, the condition of non-exceedance of the admissible load multiplier was satisfied. Numpress Explore software communicates with the Krata software. The latter was used to compute the values necessary to define the limit function for subsequent sets of random variables. Next, the reliability analysis method was chosen and computations began. The task ended with the generation of information that contained the values of the failure probability, reliability index, and elasticity index. 
Table 2. Description of random variables.

\begin{tabular}{|c|c|c|c|c|c|c|}
\hline \multirow[b]{2}{*}{ Random Variable } & \multirow[b]{2}{*}{ Mean Value $\overline{X_{i}}$} & \multirow{2}{*}{$\begin{array}{c}\text { Probability } \\
\text { Distribution } \\
\text { Type }\end{array}$} & \multicolumn{2}{|c|}{ Case 1} & \multicolumn{2}{|c|}{ Case 2} \\
\hline & & & $\begin{array}{c}\text { Standard } \\
\text { Deviation } \\
\sigma_{1, \mathrm{i}} \\
\end{array}$ & $\begin{array}{l}\text { Variation } \\
\text { Coefficient }\end{array}$ & $\begin{array}{c}\text { Standard } \\
\text { Deviation } \\
\sigma_{2, \mathrm{i}} \\
\end{array}$ & $\begin{array}{l}\text { Variation } \\
\text { Coefficient }\end{array}$ \\
\hline Load $P$ & 1 & Normal & 0.1 & $10 \%$ & 0.1 & $10 \%$ \\
\hline Coordinate " $\mathrm{z}$ " of node $1-Z_{1}$ & 1.6465 & Normal & 0.16465 & $10 \%$ & 0.082325 & $5 \%$ \\
\hline Coordinate " $\mathrm{z}$ " of node $2-Z_{2}$ & 1.432 & Normal & 0.1432 & $10 \%$ & 0.0716 & $5 \%$ \\
\hline Coordinate " $\mathrm{z}$ " of node $5-Z_{5}$ & 1.432 & Normal & 0.1432 & $10 \%$ & 0.0716 & $5 \%$ \\
\hline Coordinate " $\mathrm{z}$ " of node $6-Z_{6}$ & 1.432 & Normal & 0.1432 & $10 \%$ & 0.0716 & $5 \%$ \\
\hline Coordinate " $\mathrm{z}$ " of node $7-Z_{7}$ & 1.432 & Normal & 0.1432 & $10 \%$ & 0.0716 & $5 \%$ \\
\hline Coordinate " $\mathrm{z}$ " of node $8-Z_{8}$ & 1.432 & Normal & 0.1432 & $10 \%$ & 0.0716 & $5 \%$ \\
\hline Coordinate " $\mathrm{z}$ " of node $9-Z_{9}$ & 1.432 & Normal & 0.1432 & $10 \%$ & 0.0716 & $5 \%$ \\
\hline Coordinate " $\mathrm{z}$ " of node $10-Z_{10}$ & 1.14 & Normal & 0.114 & $10 \%$ & 0.057 & $5 \%$ \\
\hline Coordinate " $\mathrm{z}$ " of node $15-Z_{15}$ & 1.14 & Normal & 0.114 & $10 \%$ & 0.057 & $5 \%$ \\
\hline Coordinate " $\mathrm{z}$ " of node $16-Z_{16}$ & 1.14 & Normal & 0.114 & $10 \%$ & 0.057 & $5 \%$ \\
\hline Coordinate " $\mathrm{z}$ " of node $17-Z_{17}$ & 1.14 & Normal & 0.114 & $10 \%$ & 0.057 & $5 \%$ \\
\hline
\end{tabular}

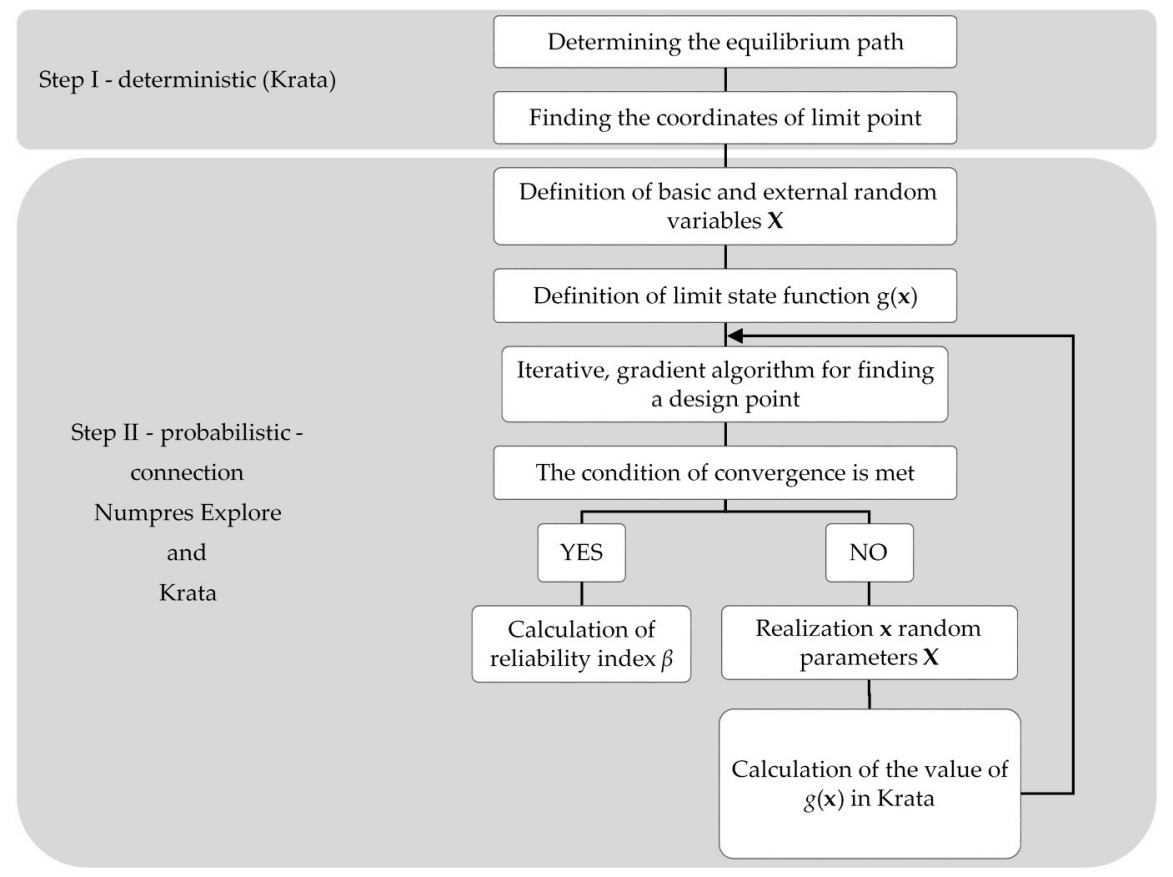

Figure 6. Procedure of the analysis.

In this paper, the impact of changes in the standard deviation of random variables describing coordinates of nodes $Z_{i} i=1, \ldots, 17$ on the reliability index $\beta$ is analyzed. Two cases were considered, in which the variation coefficient of coordinates $Z_{i}$ was modified. The variation coefficient of $10 \%$ was adopted for the first case, whereas for the other case it was $5 \%$. Random variable notations correspond to node numbers in Table 1 . Changing the standard deviation of random variables $Z_{i} i=1, \ldots, 17$ reflects the imperfections of the nodes position in the probabilistic description. In both cases, a constant variation coefficient of $10 \%$ was assumed for load $P$.

Figure 7 shows how the reliability index $\beta$ depends on the load multiplier $\mu$ for both cases. Values of the reliability index and failure probability for selected computational steps are collated in Table 3. 
Table 3. Values of the reliability index $\beta$ and failure probability $P_{\mathrm{f}}$.

\begin{tabular}{cccccc}
\hline & & \multicolumn{2}{c}{ Case 1 } & \multicolumn{2}{c}{ Case 2 } \\
\cline { 3 - 6 } Load Multiplier $\mu$ & $\begin{array}{c}\text { Displacement } \boldsymbol{q}_{\mathbf{1}} \\
{[\mathrm{mm}]}\end{array}$ & $\begin{array}{c}\text { Failure } \\
\text { Probability } \\
\boldsymbol{P}_{\mathbf{f}}\end{array}$ & $\begin{array}{c}\text { Reliability } \\
\text { Index } \\
\boldsymbol{\beta}\end{array}$ & $\begin{array}{c}\text { Failure } \\
\text { Probability } \\
\boldsymbol{P}_{\mathbf{f}}\end{array}$ & $\begin{array}{c}\text { Reliability } \\
\text { Index } \\
\boldsymbol{\beta}\end{array}$ \\
\hline 7.07 & 18.54 & 0.000248568 & 3.48229 & $6.30709 \times 10^{-9}$ & 5.69121 \\
14.19 & 40.40 & 0.0807931 & 1.39976 & 0.0058181 & 2.52299 \\
16.31 & 47.80 & 0.148813 & 1.04154 & 0.0286027 & 1.90174 \\
18.16 & 54.77 & 0.217846 & 0.77949 & 0.0755421 & 1.43571 \\
22.87 & 75.62 & 0.393263 & 0.270823 & 0.305856 & 0.507631 \\
23.85 & 81.00 & 0.42604 & 0.186542 & 0.362944 & 0.3506 \\
\hline
\end{tabular}

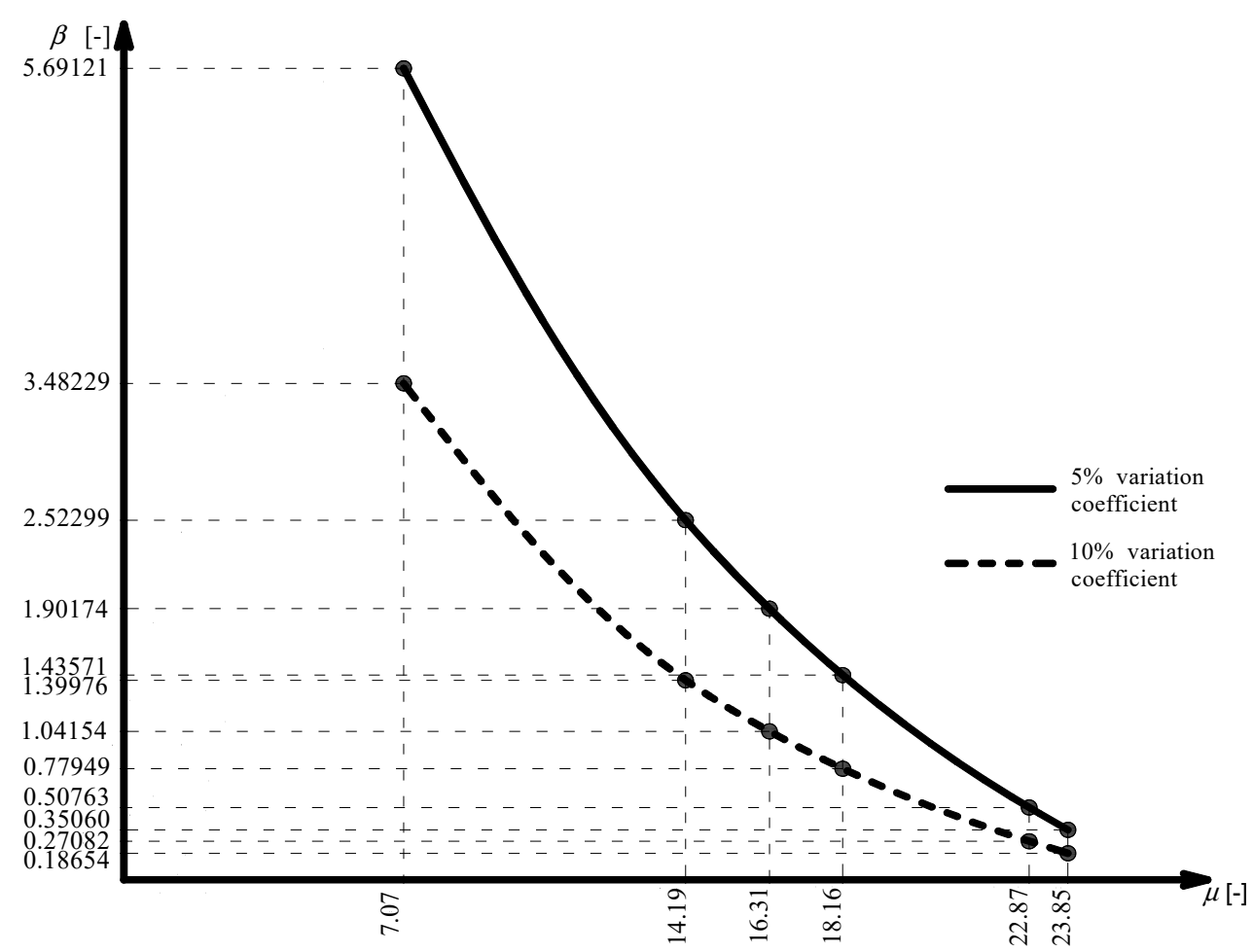

Figure 7. The dependence between the reliability index $\beta$ and the load multiplier $\mu$.

Additionally, this paper examins the elasticity index $\mathrm{E}_{\beta}\left(\mathrm{p}_{\mathrm{i}}\right)$. Figure 8 shows the deformed form of the considered structure. It is necessary to pay attention to the direction of displacement of individual nodes. The upper node, No. 1, and the middle nodes, Nos. 2 to 9, are moving downwards, relative to the undeformed form of the structure, while the lower nodes, Nos. 10 to 17, are moving upwards. Figures 9-12 show the values of the elasticity index $E_{\beta}\left(p_{i}\right)$ with respect to the mean value in the first and the last computational step for all random variables. For the cases of concern, changes in the values of the elasticity index $\mathrm{E}_{\beta}\left(\mathrm{p}_{\mathrm{i}}\right)$ for variables $P$ and $\mathrm{Zi}$, depending on the load value, are shown in Table 4. We can observe the occurrence of positive and negative values of the elasticity index, which depends on the direction of the node's displacement. 

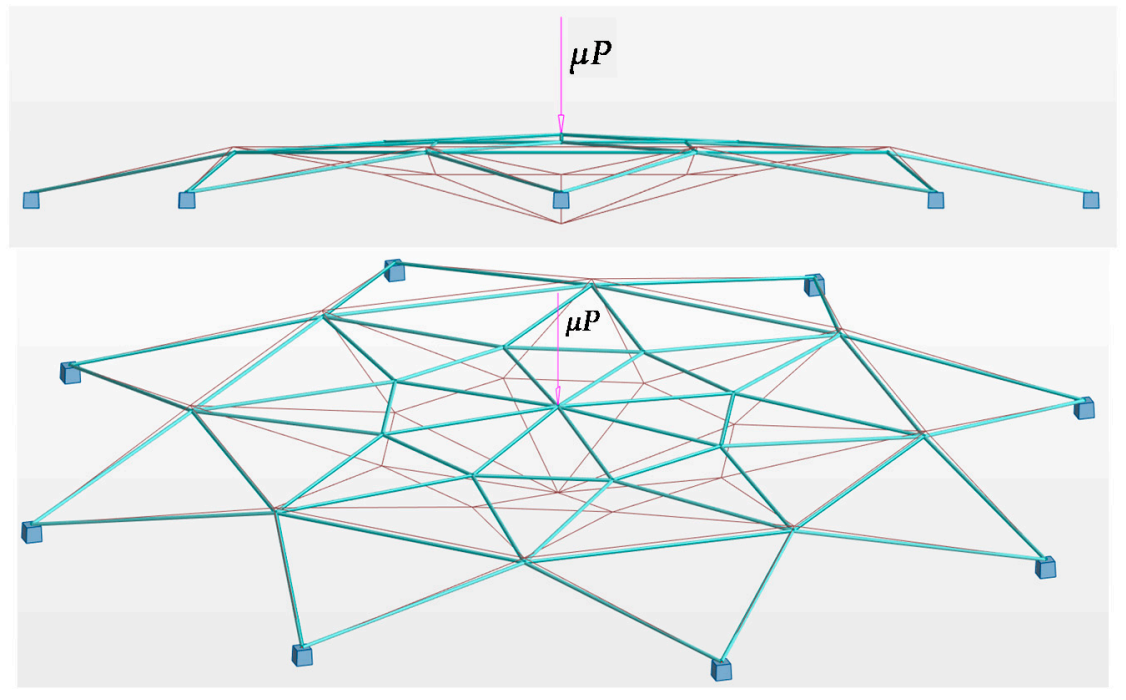

Figure 8. Deformed form of the structure.

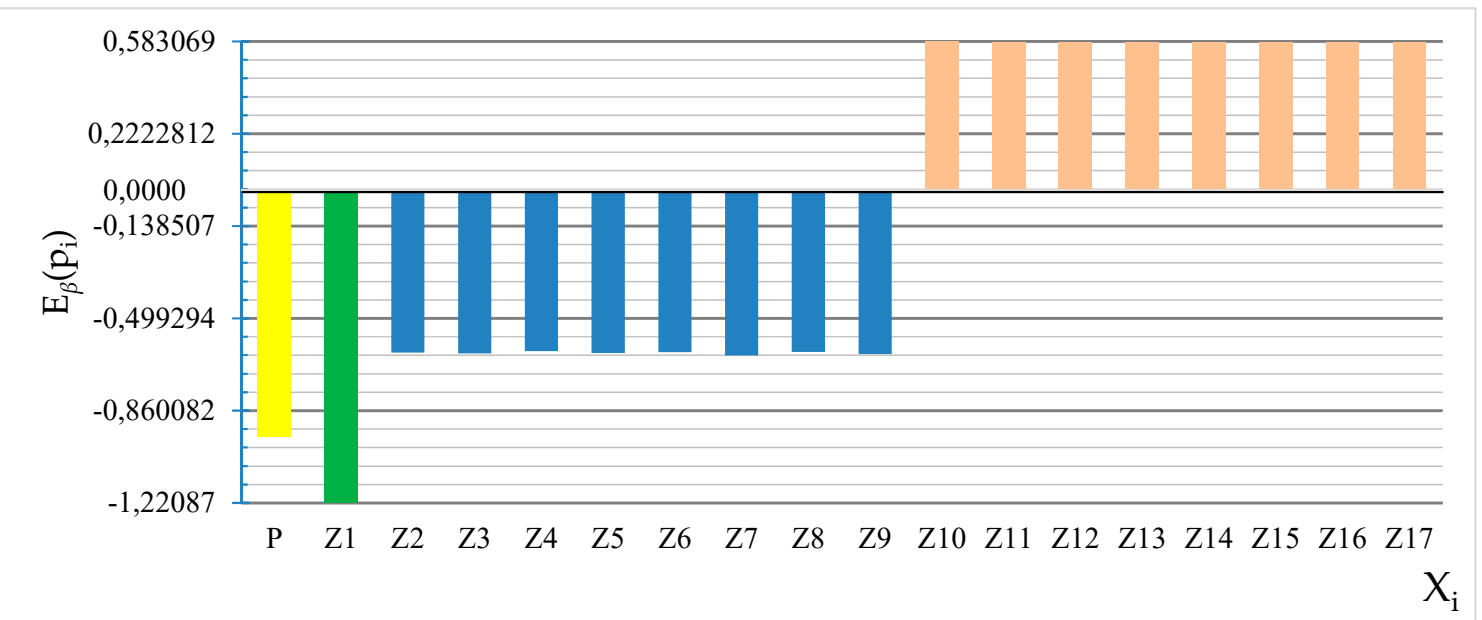

Figure 9. Elasticity index $\mathrm{E}_{\beta}\left(\mathrm{p}_{\mathrm{i}}\right)$ with respect to the mean value $\left(\mathrm{p}_{\mathrm{i}}=\overline{X_{\mathbf{i}}}\right.$ ) for Case 1 and the load multiplier $\mu=7.07$.

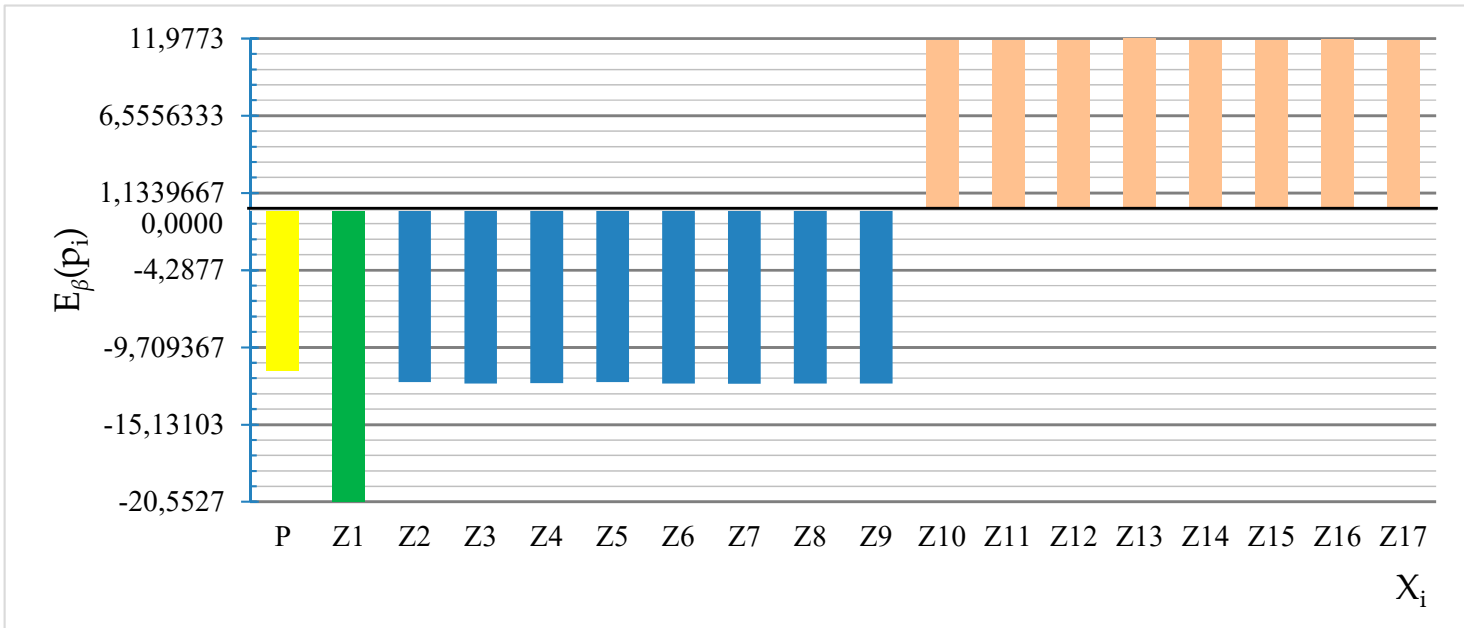

Figure 10. Elasticity index $E_{\beta}\left(p_{i}\right)$ with respect to the mean value $\left(p_{i}=\overline{X_{i}}\right)$ for Case 1 and the load multiplier $\mu=23.85$. 


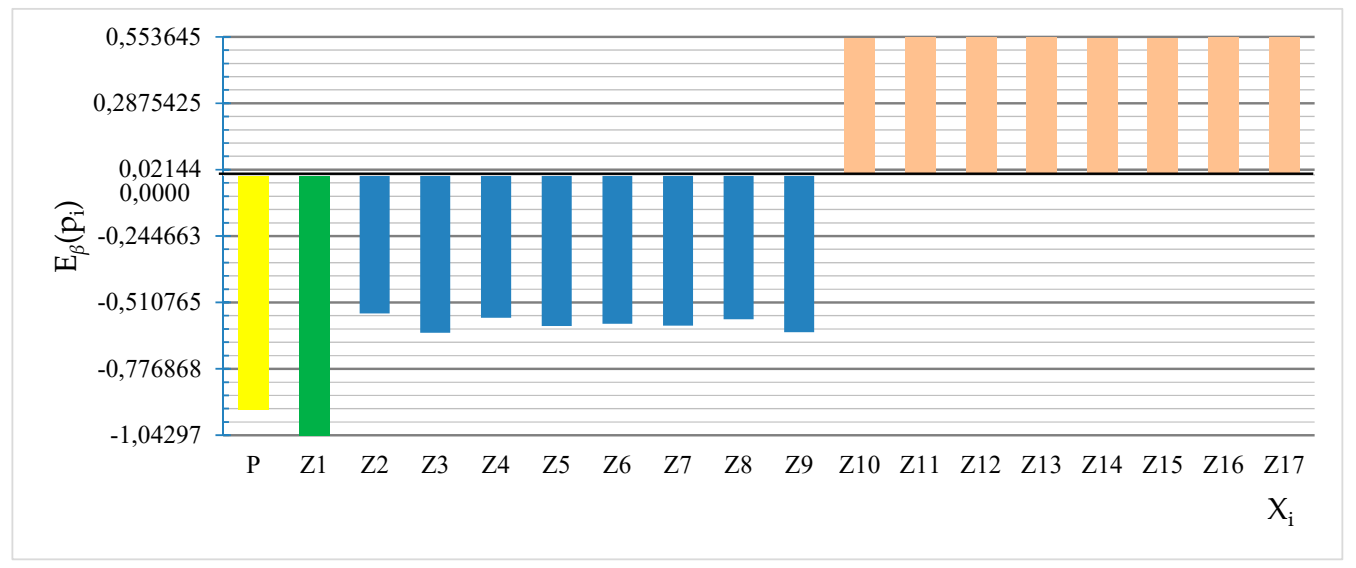

Figure 11. Elasticity index $E_{\beta}\left(p_{i}\right)$ with respect to the mean value $\left(p_{i}=\overline{X_{i}}\right)$ for Case 2 and the load multiplier $\mu=7.07$.

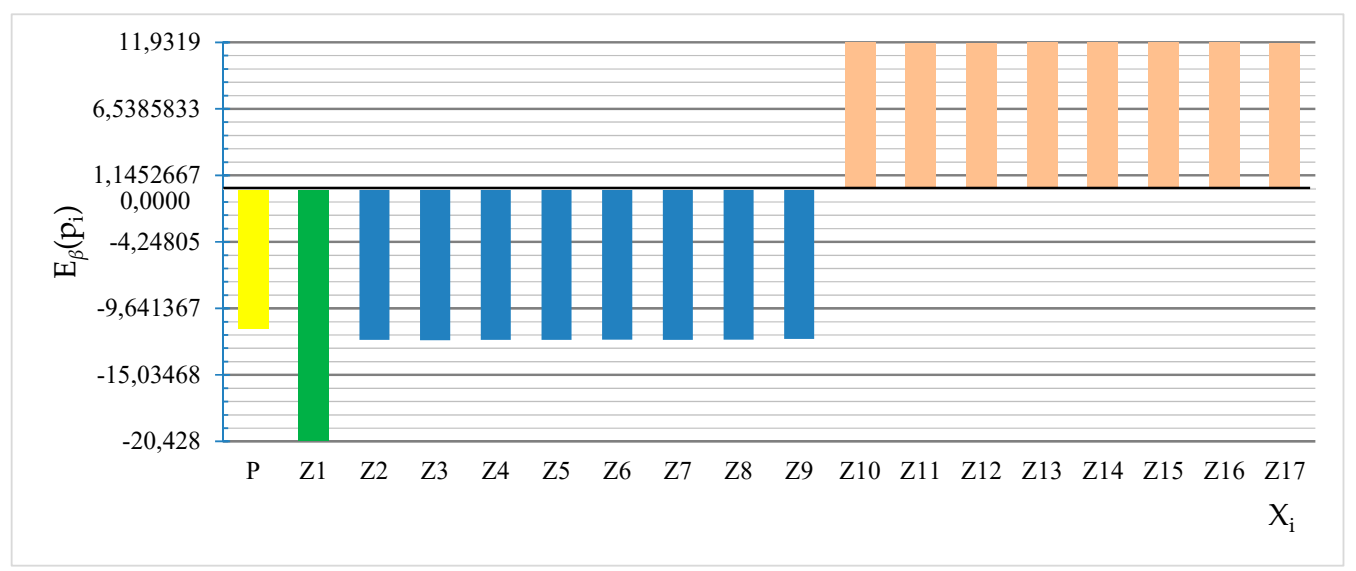

Figure 12. Elasticity index $E_{\beta}\left(p_{i}\right)$ with respect to the mean value $\left(p_{i}=\overline{X_{i}}\right)$ for Case 2 and the load multiplier $\mu=23.85$.

Table 4. Values of the elasticity index $\mathrm{E}_{\beta}\left(\mathrm{p}_{\mathrm{i}}\right)$ with respect to the mean value depending on the load multiplier applied.

\begin{tabular}{ccccc}
\hline & \multicolumn{2}{c}{ Case $\mathbf{1}$} & \multicolumn{2}{c}{ Case 2 } \\
\hline $\mathrm{P}$ & $\mu=7,07$ & $\mu=23,85$ & $\mu=7,07$ & $\mu=23,85$ \\
$\mathrm{Z}_{1}$ & $-0,960682$ & $-11,3796$ & $-0,94165$ & $-11,295$ \\
$\mathrm{Z}_{2}$ & $-0,633033$ & $-20,5527$ & $-1,04297$ & $-20,428$ \\
$\mathrm{Z}_{3}$ & $-0,636345$ & $-12,1532$ & $-0,55432$ & $-12,1929$ \\
$\mathrm{Z}_{4}$ & $-0,627177$ & $-12,248$ & $-0,63249$ & $-12,2128$ \\
$\mathrm{Z}_{5}$ & $-0,634882$ & $-12,2261$ & $-0,57223$ & $-12,1834$ \\
$\mathrm{Z}_{6}$ & $-0,63134$ & $-12,1534$ & $-0,60514$ & $-12,2013$ \\
$\mathrm{Z}_{7}$ & $-0,643971$ & $-12,2363$ & $-0,59676$ & $-12,1821$ \\
$\mathrm{Z}_{8}$ & $-0,630684$ & $-12,2566$ & $-0,60399$ & $-12,2017$ \\
$\mathrm{Z}_{9}$ & $-0,638158$ & $-12,2457$ & $-0,57788$ & $-12,1823$ \\
$\mathrm{Z}_{10}$ & 0,583069 & $-12,2553$ & $-0,62899$ & $-12,1231$ \\
$\mathrm{Z}_{11}$ & 0,578446 & 11,8805 & 0,546972 & 11,9319 \\
$\mathrm{Z}_{12}$ & 0,580928 & 11,8845 & 0,551486 & 11,8314 \\
$\mathrm{Z}_{13}$ & 0,580211 & 11,8773 & 0,552808 & 11,8252 \\
$\mathrm{Z}_{14}$ & 0,58106 & 11,9773 & 0,551094 & 11,9262 \\
$\mathrm{Z}_{15}$ & 0,578546 & 11,8772 & 0,548862 & 11,9283 \\
$\mathrm{Z}_{16}$ & 0,578429 & 11,8836 & 0,548516 & 11,9291 \\
$\mathrm{Z}_{17}$ & 0,58093 & 11,8875 & 0,55195 & 11,9279 \\
\hline & & 11,8778 & 0,553645 & 11,8224 \\
\hline
\end{tabular}


In order to better illustrate the influence of random variables $P$ and $Z_{\mathrm{i}}$ on the values of the reliability index $\beta$, the values of the elasticity index were presented in relation to the standard deviation (Table 5).

Table 5. Values of the elasticity index $\mathrm{E}_{\beta}\left(\mathrm{p}_{\mathrm{i}}\right)$ with respect to the standard deviation, depending on the load multiplier applied.

\begin{tabular}{ccccc}
\hline & \multicolumn{2}{c}{ Case 1} & \multicolumn{2}{c}{ Case 2} \\
\hline $\mathrm{P}$ & 0,060838 & $\mu=23,85$ & $\mu=7,07$ & $\mu=23,85$ \\
$\mathrm{Z}_{1}$ & 0,075018 & 0,00047 & 0,683858 & 0,00588722 \\
$\mathrm{Z}_{2}$ & 0,010806 & 0,003919 & 0,0575702 & 0,00598635 \\
$\mathrm{Z}_{3}$ & 0,01099 & 0,00056 & 0,00792583 & 0,00085315 \\
$\mathrm{Z}_{4}$ & 0,010546 & 0,000565 & 0,0107745 & 0,00085699 \\
$\mathrm{Z}_{5}$ & 0,010921 & 0,000567 & 0,0085271 & 0,000851656 \\
$\mathrm{Z}_{6}$ & 0,010715 & 0,000561 & 0,00969135 & 0,000852898 \\
$\mathrm{Z}_{7}$ & 0,011342 & 0,000566 & 0,00941762 & 0,000848981 \\
$\mathrm{Z}_{8}$ & 0,010686 & 0,000568 & 0,00963334 & 0,000856157 \\
$\mathrm{Z}_{9}$ & 0,011073 & 0,00057 & 0,00871643 & 0,000851986 \\
$\mathrm{Z}_{10}$ & 0,011552 & 0,000533 & 0,0106294 & 0,000841353 \\
$\mathrm{Z}_{11}$ & 0,011284 & 0,000534 & 0,00893249 & 0,000836612 \\
$\mathrm{Z}_{12}$ & 0,011468 & 0,000533 & 0,00910208 & 0,000821875 \\
$\mathrm{Z}_{13}$ & 0,011429 & 0,000542 & 0,00917403 & 0,000820686 \\
$\mathrm{Z}_{14}$ & 0,01147 & 0,000528 & 0,00910028 & 0,000835488 \\
$\mathrm{Z}_{15}$ & 0,011286 & 0,000534 & 0,0090027 & 0,000833421 \\
$\mathrm{Z}_{16}$ & 0,011275 & 0,000534 & 0,00901152 & 0,000836247 \\
$\mathrm{Z}_{17}$ & 0,011464 & 0,000528 & 0,00912094 & 0,000832002 \\
\hline
\end{tabular}

For the cases of concern, a major difference in the reliability index values was observed (Figure 7). For Case 1, the maximum value of the reliability index was 3.48229, which constitutes $61.19 \%$ of the value of Case 2. With an increase in the load applied, the reliability index dropped to the following values: 0.3506 for the $5 \%$ case and 0.186542 for the $10 \%$ of index variation. The analysis demonstrated a significant increase in the value of the elasticity index $\mathrm{E}_{\beta}\left(\mathrm{p}_{\mathrm{i}}\right)$, with respect to the mean value. As regards Case 1, the index value increased from 0.96062 to 11.3796 for random variable $P$, and from 1.22087 to 20.5527 for random variable $Z_{1}$. With Case 2, the increase was from 0.941646 to 11.295 for random variable $P$, and from 1.04297 to 20.428 for random variable $Z_{1}$. Similarly, in the case of the elasticity index, with respect to the standard deviation, we can see that, for the random variable $Z_{1}$, the values were several times higher than for other random variables, and the random variable $P$, in the case for the load multiple value of 7.07, takes values much higher than the others. It was observed that as the limit value of the load multiplier was approached, the significance of the random variable that describes load $P$ was reduced. In the last step of the analysis, the obtained values of the elasticity index $E_{\beta}\left(p_{i}\right)$ for random variable $P$ were lower than the values of the elasticity index $E_{\beta}\left(p_{i}\right)$ for the remaining random variables. A change in the variation index of random variables from 10 to $5 \%$ led to an increase in the reliability index, with respect to the mean value by approx. $63.43 \%$.

\section{Conclusions}

Building the mathematical model of a problem, the designer must make a decision as to which design parameters should be treated as deterministic or random. It must be remembered that, in reality, every physical quantity is a random variable; however, for computational purposes, a part of them are assumed as deterministic parameters. Identification of variables determines the solution of the problem in a significant way; therefore, it is essential to investigate the elasticity index. In this paper, the examination of the elasticity index $\mathrm{E}_{\beta}\left(\mathrm{p}_{\mathrm{i}}\right)$ indicates a uniform increment of the index value for all random variables taken into account. Such a change in the elasticity index shows that when 
conducting the reliability analysis of the lattice dome, it is necessary to consider all random variables adopted in the description.

After considering the randomness of a given parameter, it is necessary to carefully determine the description of distribution parameters. These parameters have an effect on the results of analysis. In this article, to describe all random variables, the normal type of distribution is used, described by the mean value and standard deviation. Two cases of the variation coefficient, namely $10 \%$ and $5 \%$, for random variables of $Z_{1}$ to $Z_{17}$ were taken into account. Changing the standard deviation of random variables $Z_{i}$ reflects the imperfections of the nodes position in the probabilistic description. A constant variation coefficient of $10 \%$ for the random variable $P$ was adopted, which corresponds to the assumed unit load. For the cases of concern, a major difference in the reliability index values was observed (Figure 7). On the basis of the analyses conducted for the paper, it can be stated that adequate probabilistic description of the node location significantly affects the structure reliability.

The approach addressed in the Eurocodes makes it impossible to quantitatively assess. It only gives an answer if the structure is unreliable or safe. This is a qualitative assessment. The FORM, thanks to the reliability index, gives this possibility. In probabilistic methods, the information on distribution types of the design variables and their parameters is utilized. Such a formulation makes it possible to explicitly account for randomness in the design process. Thus, it is possible to develop a mathematical model to estimate the probability of a specified behavior of the structure. This paper shows that, with the reliability analysis methods, it was possible to find out the failure probability level while moving along the load-displacement path towards the limit point. Reliability analysis was also employed to find the sensitivity of the reliability index to the mean values or standard deviation of random variables by calculating the elasticity index. With the growth of the degree of complication that occurs in practical issues of designing, explicit reliability methods lose their functionality. In connection with the above, the present study proposes the possibility of the use of interface between methods, dealing with reliability analysis and the numerical methods of the calculation of engineering structures, e.g., Finite Element Method.

With the growth of the degree of complication that occurs in practical issues of designing, explicit reliability methods lose their functionality. In connection with the above, the present study proposes the possibility of the use of interface between methods, dealing with reliability analysis and the numerical methods of the calculation of engineering structures, e.g., Finite Element Method.

Author Contributions: Introduction was prepared by P.Z. and U.R. Definition and properties of analysis were written by P.Z. and U.R. Results were obtained by P.Z. and U.R. The analysis of the results and conclusions were written by P.Z. and U.R.

Funding: This research received no external funding.

Conflicts of Interest: The authors declare no conflict of interest.

\section{References}

1. Madsen, H.O.; Krenk, S.; Lind, N.C. Methods of Structural Safety; Prentice-Hall: Upper Saddle River, NJ, USA, 1986.

2. Melchers, R.E. Structural Reliability Analysis and Predictions, 2nd ed.; Wiley: Hoboken, NJ, USA, 1999.

3. Ditlevsen, O.; Madsen, H.O. Structural Reliability Methods; Wiley: Hoboken, NJ, USA, 1996.

4. Thoft-Christensen, P.; Baker, M.J. Structural Reliability Theory and its Applications; Springer: Berlin, Germany, 1982.

5. Augusti, G.; Baratta, A.; Casciati, F. Probabilistic Methods in Structural Engineering; Chapman and Hall: London, UK, 1984.

6. Harr, M.E. Reliability-Based Design in Civil Engineering; McGraw-Hill: New York, NY, USA, 1987.

7. Nowak, A.S.; Collins, K.R. Reliability of Structures; McGraw-Hill Higher Education: New York, NY, USA, 2000.

8. Hasofer, A.M.; Lind, N.C. Exact and invariant second moment code format. J. Engin. Mech. Div. ASCE 1974, 100, 111-121.

9. Cornell, C.A. A probability-based structural code. J. Am. Concr. Inst. 1969, 66, 974-985. 
10. Rackwitz, R.; Fiessler, B. Structural reliability under combined random load sequences. Comput. Struct. 1978, 9, 489-494. [CrossRef]

11. Hohenbichler, M.; Rackwitz, R. Non-normal dependent vectors in structural safety. J. Engin. Mech. Div. ASCE 1981, 107, 1227-1238.

12. Rosenblatt, M. Remarks on a Multivariate Transformation. Ann. Math. Stat. 1952, 23, 470-472. [CrossRef]

13. Der Kiureghian, A.; Liu, P.L. Structural reliability under incomplete probability information. J. Eng. Mech. ASCE 1986, 112, 85-104. [CrossRef]

14. Hisada, T.; Nakagiri, S. Role of the stochastic finite element method in structural safety and reliability. In Proceedings of the 4th International Conference on Structural Society Safety Reliability, Cobe, Japan, 27-29 May 1985; pp. 385-394.

15. Liu, W.K.; Mani, A.; Belytschko, T. Finite elements methods in probabilistic mechanics. Probabilistics Eng. Mech. 1987, 2, 201-213. [CrossRef]

16. Shinozuka, M. Basic issues in stochastic finite element analysis. In Proceedings of the Fifth International Conference on Applications of Statistics and Probability in Soil and Structural Engineering, University of British Columbia, Vancouver, BC, Canada, 25-29 May 1987; pp. 507-520.

17. Li, C.C.; der Kiureghian, A. Optimal discretization of random fields. J. Engin. Mech. ASCE 1993, 119, 1136-1154. [CrossRef]

18. Matthies, H.G.; Brenner, C.E.; Bucher, C.G.; Guedes Soares, C. Uncertainties in probabilistic numerical analysis of structures and solids-Stochastics finite elements. Struct. Saf. 1997, 19, 283-336. [CrossRef]

19. Pellissetti, M.F.; Schuëller, G.I. On general purpose software in structural reliability-An overview. Struc. Saf. 2006, 28, 3-16. [CrossRef]

20. Reh, S.; Beley, J.D.; Mukherjee, S.; Khor, E.H. Probabilistic finite element analysis using ANSYS. Struct. Saf. 2006, 28, 17-43. [CrossRef]

21. Der Kiureghian, A.; Haukaas, T.; Fujimura, K. Structural reliability software at the University of California, Berkeley. Struct. Saf. 2006, 28, 44-67. [CrossRef]

22. Schuëller, G.I.; Pradlwarter, H.J. Computational stochastic structural analysis (COSSAN)-software tool. Struct. Saf. 2006, 28, 68-82. [CrossRef]

23. Thacker, B.H.; Riha, D.S.; Fitch, S.K.H.; Huyse, L.J.; Pleming, J.B. Probabilistic engineering analysis using the NESSUS software. Struct. Saf. 2006, 28, 83-107. [CrossRef]

24. Gollwitzer, S.; Kirchgabner, B.; Fischer, R.; Rackwitz, R. PERMAS-RA/STRUREL system of programs for probabilistic reliability analysis. Struct. Saf. 2006, 28, 108-129. [CrossRef]

25. Lemaire, M. Pendola phimeca-soft M. Struct. Saf. 2006, 28, 130-149. [CrossRef]

26. Tvedt, L. Proban-probabilistic analysis. Struct. Saf. 2006, 28, 150-163. [CrossRef]

27. Wu, Y.T.; Shin, Y.; Sues, R.H.; Cesare, M.A. Probabilistic function evaluation system (ProFES) for reliability-based design. Struct. Saf. 2006, 28, 164-195. [CrossRef]

28. Lin, H.Z.; Khalessi, M.R. General outlook of UNIPASSV5.0: A general-purpose probabilistic software system. Struct. Saf. 2006, 28, 196-216. [CrossRef]

29. Schuëller, G.I.; Stix, R. A critical appraisal of methods to determine failure probabilities. Struct. Saf. 1987, 4, 293-309. [CrossRef]

30. Hohenbichler, M.; Rackwitz, R. Improvement of second-order reliability estimates by importance sampling. J. Engin. Mech. ASCE 1988, 114, 2195-2199. [CrossRef]

31. Doliński, K. First-order second-moment approximation in reliability of structural systems: Critical review and alternative approach. Struct. Saf. 1983, 1, 211-231. [CrossRef]

32. Rubinstein, R.Y. Simulation and the Monte Carlo Method; Wiley: Hoboken, NJ, USA, 1981.

33. Obara, P.; Radoń, U.; Zabojszcza, P.; Mochocki, W. Effects of single-layer truss dome geometry on critical load capacity. Struct. Environ. 2017, 3, 152-164.

34. Zabojszcza, P.; Radoń, U.; Obara, P. Impact of single-layer dome modelling on the critical load capacity. Matec. Web Conf. 2018, 219. [CrossRef]

35. Zabojszcza, P.; Radoń, U. Effect of increased density of nodes in geodesic dome on its critical load capacity. IOP Conf. Ser. Mater. Sci. Eng. 2019, 471. [CrossRef]

36. Riks, E. The application of Newton's method to the problem of elastic stability. J. Appl. Mech. 1972, 39, 1060-1065. [CrossRef] 
37. Riks, E. An incremental approach to the solution of snapping and buckling problems. Int. J. Solids Struct. 1979, 15, 529-551. [CrossRef]

38. Zhao, C.; Zhao, Y.; Ma, J. The stability of new single-layer combined lattice shell based on aluminum alloy honeycomb panels. Appl. Sci. 2017, 7, 1150. [CrossRef]

39. Galambos, T.V. Guide to Stability Design for Metal Structures; Wiley and Sons: Hoboken, NJ, USA, 1998.

40. Thompson, J.M.T.; Hunt, G.W. A General Theory of Elastic Stability; Wiley and Sons: Hobooken, NJ, USA, 1973.

41. Pignatero, M.; Rizzi, N.; Luongo, A. Stability, Bifurcation and Postcritical Behavior of Elastic Structures; Elsevier: Amsterdam, The Netherlands, 1991.

42. Stocki, R.; Kolanek, K.; Knabel, J.; Tauzowski, P. FE based structural reliability analysis using STAND environment. Comput. Assist. Mech. Eng. Sci. 2009, 16, 35-58.

43. Lasota, R.; Stocki, R.; Tauzowski, P.; Szolc, T. Polynomial chaos expansion method in estimating probability distribution of rotor-shaft dynamic responses. Bull. Pol. Acad. Sci. Tech. Sci. 2015, 63, 413-422. [CrossRef]

44. Szolc, T.; Tauzowski, P.; Stocki, R.; Knabel, J. Damage identification in vibrating rotor-shaft systems by efficient sampling approach. Mech. Syst. Signal. Process. 2009, 23, 1615-1633. [CrossRef]

45. Stocki, R.; Tauzowski, P.; Knabel, J. Reliability analysis of a crashed thin-walled s-rail accounting for random spot weld failures. Int. J. Crashworthiness 2008, 13, 693-706. [CrossRef]

46. European Committee for Standardization. Basis of Structural Design; Technical Report PN-EN-1990:2002; European Committee for Standardization: Brussels, Belgium, 2005.

47. Schittkowski, K. The nonlinear programming method of Wilson, Han and Powell with an augmented Lagrangian type line search function, part 1: Convergence analysis. Numer. Math. 1982, 38, 83-114. [CrossRef]

48. Schittkowski, K.; Zillober, C.; Zotemantel, R. Numerical comparison of nonlinear programming algorithms for structural optimization. Struct. Multidiscip. Optim. 1994, 7, 1-19. [CrossRef]

49. Budnick, F.S. Finite Mathematics with Applications; McGraw-Hill: New York, NY, USA, 1985.

50. Radoń, U. Reliability analysis of misses truss. Arch. Civ. Mech. Eng. 2011, 11, 723-738. [CrossRef]

51. Radoń, U.; Dudzik, A. The evaluation of algorithms for determination of the reliability index. Arch. Civ. Eng. 2015, 3, 133-147.

52. Radoń, U.; Dudzik, A. The Reliability Assessment of a Steel Industrial Hall, Advances in Mechanics: Theoretical, Computational and Interdisciplinary Issues; Taylor \& Francis Group: London, UK, 2016; pp. 163-166.

53. NUMPRESS. Available online: http://numpress.ippt.pan.pl/opis.html (accessed on 4 June 2019). 